\title{
Justiça restaurativa e direitos fundamentais: a narratividade nos círculos de construção de paz
}

\author{
Restorative justice and fundamental rights: narrativity \\ in the circles of peace-building
}

VALÉRIA BRESSAN CANDIDO Tribunal de Justiça do Estado de São Paulo. São Paulo-SP - Brasil

Luci Mendes de Melo Bonini Universidade de Mogi das Cruzes, Centro de Ciências Humanas. Mogi das Cruzes, SP - Brasil

Resumo Este estudo tem o objetivo de aproximar a teoria da linguagem sobre o dialogismo de Bakhtin com as práticas dos "Círculos de Construção de Paz" preconizados por Key Pranis, dentro dos quais o diálogo é uma constante. Somos seres de linguagem e, por intermédio dela, podemos expressar nossos sentimentos, medos e expectativas e assim resgatar o nosso lugar no mundo como sujeito de direito. A proposta é potencializar o entendimento das narrativas empregadas nos Círculos Restaurativos fundamentando-se na filosofia de Bakhtin. O método que aqui se utilizou foi o da revisão bibliográfica, a fim de desenvolver um estudo de características ensaísticas. Como conclusões, pode-se adiantar que a língua é o meio usado para a comunicação, cujo sentido mais amplo é o de tornar comum, o que por sua vez pode ser capaz de restaurar a paz dentro de uma comunidade.

Palavras-chave: Justiça Restaurativa. Construção de Paz. Bakhtin. Narratividade. Pensamento bakhtiniano. 
Abstract This study is intended to approximate the language theories of Bakhtin circles practices of building Peace, within which dialogue is a constant. We are beings of language and, through it, we can express our feelings, fears and expectations and thus redeem our place in the world as a subject of law. The proposal is to enhance the understanding of the narrations used in Restorative Circles based on philosophy of Bakhtin. The method used here was the literature review to develop an essay. The conclusions it was demonstrated that language is the medium used for communication, whose broader sense is to make common thoughts and acts that also may be able to restore peace within a community.

Key-words: Restorative Justice. Peace Building. Bakhtin. NarrativITY. BAKHTIN THOUGHT.

\section{INTRODUÇÃo}

A Justiça restaurativa destina-se a representar o ideal de que os infratores devem rever o mal que fizeram à vítima e à sociedade como um todo, trabalhando para reconstituir os males físicos e psicológicos causados na sociedade onde o crime ocorreu. Ela pode ser um procedimento eficaz utilizado para pequenos crimes e por isso pode ser vista como benéfica pelo bem que faz para a comunidade, pois se entende que as pessoas comuns afetadas pelos delitos precisam tomar parte ativa em decidir o que deve acontecer para solucionar o conflito, pois permite que as vítimas se encontrem com o agressor e dialoguem sobre o que aconteceu.

A Justiça Restaurativa é um processo circular, colaborativo, voltado para a resolução de um conflito, que envolve a participação maior do infrator e da vítima. Surgiu no exterior, na cultura anglo-saxã, e as primeiras experiências vieram do Canadá e da Nova Zelândia e ganharam relevância em várias partes do mundo.

O círculo é um lugar onde as pessoas afetadas pelo dano (vítimas, ofensores e comunidade) se encontram para achar um modo de solucionar um conflito, reconhecer responsabilidades, recuperar o dano, por 
isso entende-se que a narratividade é fundamental. Peña (2015) afirma que os conflitos são histórias e a forma que o homem entende a vida o faz por meio da linguagem, assim é por intermédio das narrativas que as partes se enxergam como contrárias ou complementares.

O diálogo, a linguagem, é o meio pelo qual o homem constrói a sociedade, nesse ponto, insere-se neste contexto a teoria de Mikhail Bakhtin. Esse autor dedicou a vida à definição de noções, conceitos e categorias de análise da linguagem com base em discursos cotidianos, artísticos, filosóficos, científicos e institucionais. Foi um dos mais destacados pensadores de uma rede de profissionais preocupados com as formas de estudar linguagem, literatura e arte, que incluía o linguista Valentin Voloshinov (1895-1936) e o teórico literário Pavel Medvedev (1891-1938).

Um dos aspectos mais inovadores da produção do Círculo de Bakhtin, como ficou conhecido o grupo, foi enxergar a linguagem como um constante processo de interação mediado pelo diálogo - e não apenas como um sistema autônomo. Os argumentos fenomenológicos apresentados pelo jovem Bakhtin são dirigidos contra as abstrações da filosofia racionalista e do positivismo contemporâneo.

Os círculos de construção de paz são, dessa forma, fenômenos onde as narrativas se desenrolam. Bakhtin, intelectual russo, criou um grupo multidisciplinar, que se reuniu regularmente entre 1919 e 1929, cujos objetivos eram, dentro de círculos, debater ideias, mergulhar fundo nas discussões de filósofos do passado, sem deixar de envolver-se criticamente com autores de seu tempo: a paixão pela linguagem descortinou-se em Leningrado, num momento bastante influenciado pelo pensamento marxista.

Os estudos do grupo se voltaram para o universo da criação ideológica -manifestações superestruturais, entre elas a arte, a ciência, a filosofia, o direito, a religião, a ética, a política ideologia (FARACO, 2009).

Para os integrantes do Círculo de Bakhtin, toda comunicação é a realização concreta da interação verbal, porque entende que toda palavra procede de alguém e se dirige para alguém - há um eu e outro, um eu em relação a outro (BAKHTIN, 2009). 
A comunicação, por esse entendimento, não é a expressão de algo (preexistente, interior) por alguém a alguém por meio de palavras - $\mathrm{o}$ que a caracterizaria como um mero instrumento. A comunicação, tomada como realidade fundamental da língua, é justamente o processo de expressar-se em relação ao outro, e não simplesmente para o outro. A comunicação, tomada como realidade fundamental da língua - o eu só existe em relação ao outro, e só assim pode expressar-se, o que configura a dinâmica da interação verbal/discursiva (MOLON e VIANNA, 2012).

Kearney explica que:

Toda existência humana é uma vida em busca de uma narrativa, Isto, não apenas porque ela se empenha em descobrir um padrão com o qual lidar com a experiência do caos e da confusão, mas, também, porque cada vida humana é quase sempre implicitamente uma historia (KEARNEY, 2012, p. 412).

Este estudo tem o objetivo de aproximar as teorias da linguagem de Bakhtin, que abordam a dialogicidade - diálogo como prática de ouvir/conhecer/entender o outro com as práticas dos Círculos de Construção de Paz. O processo dialógico se caracteriza como construção das alteridades, na medida em que somos seres de linguagem e, por meio dela, podemos expressar nossos sentimentos, medos e expectativas no eu mesmo e no outro, no que está fora de mim e em mim, do que está na realidade da linguagem e na realidade material. Os Círculos de Construção de Paz são um espaço intencional concebido para apoiar os participantes - ofensor x ofendido e demais árbitros num processo dialógico, para que dessa forma a cada um seja permitido que traga à tona o "melhor de si".

O método que aqui se utilizou foi o da revisão bibliográfica, fundamentada em Howard Zehr, Kay Pranys e Marshall Rosenberg, precursores dos conceitos e práticas restaurativas e nos escritos do próprio Bakhtin, a fim de desenvolver um estudo de características ensaísticas, já que para melhor desenvolvimento da aproximação a que se propõe, um estudo mais aprofundado seria necessário. Nesse sentido, este en- 
saio parte do pressuposto de que se um círculo restaurativo ou de construção de paz é fundado no diálogo, então uma teoria que dê conta de compreender o diálogo como construção de identidades e alteridades, de narrativas que as constroem como os estudos sobre dialogismo de Bakhtin, pode ser usada como base para a compreensão e o planejamento desses círculos. Também entende-se que há a possibilidade de se compreender o diálogo nos círculos como uma forma de garantir que tanto o ofensor como o ofendido e ainda a comunidade tenham preservados seus direitos fundamentais, entre os quais: a liberdade de expressão, o direito à presunção de inocência e à defesa, a restauração da dignidade da pessoa humana, como um todo.

Como conclusões, pode-se adiantar que a língua é o meio utilizado para a comunicação, cujo sentido mais amplo é o de tornar comum o que, por sua vez, pode ser capaz de restaurar a paz dentro de uma comunidade.

\section{A RELAÇÃo DE NARRATIVIDADE ENTRE OS CÍRCULOS}

Bakhtin (2009, p. 31) ensina que "tudo que é ideológico possui um significado e remete a algo situado fora de si mesmo", ou seja, tudo que é ideológico possui um signo.

No entanto, quando se faz uma analogia das relações humanas com o mundo objetivo, pode-se entender que algumas delas se parecem com uma taça de cristal quebrada e assim, ainda que coladas suas partes e ela conserve sua utilidade, não mais será um objeto perfeito, possível de reconstituir seu "status quo ante".

A língua é um composto de signos, estes por sua vez, são unidades linguísticas. Eles realizam duas operações simultâneas: refletem e refratam o mundo, sendo a refração uma condição necessária do signo, e clara, ideológica. Faraco (2009) explicita que isso se dá porque as significações não estão no signo em si, mas são construídas na dinâmica da história e estão marcadas pelas diversificadas experiências dos sujeitos, com seus valores, sua cultura, suas contradições e interesses sociais. Com a dinâmica da história, cada grupo em cada época recobre o mundo com múltiplas significações e diferentes vozes sociais que 
participam dos processos de significações, daí resultando as inúmeras semânticas, que, por sua vez, fazem emergir várias verdades, distintos pontos de vista e posições que atribuímos sentido ao mundo. Esses novos aspectos, segundo aponta Faraco (2012), dão significado ao que Bakhtin chama de línguas sociais - processos semióticos complexos utilizados pelos diversos grupos humanos.

Para o autor, a ideologia reside, precisamente, no fato de que ele se situa entre indivíduos organizados, dessa forma os signos pertencem a um terreno não natural ou interindividual, não bastando colocar face a face dois seres humanos para que os signos se constituam. Melhor dizendo, para que haja uma interação social, dialógica, é necessário que esses indivíduos estejam socialmente integrados, pois a consciência individual não pode explicar por si só, mas ao contrário, deve ela própria ser explicada a partir do meio ideológico e social, dos outros. A identidade de um se constrói nas identidades dos outros: o outro, sujeito imerso numa cultura, singular, ou o outro, o coletivo, toda uma sociedade e seus códigos, valores e crenças.

Ao se separar os fenômenos ideológicos da consciência individual, ligam-se os fenômenos às condições e às formas da comunicação/ interação social. A existência dos signos nada mais é do que a materialização dessa comunicação. É nisso que consiste a natureza de todos os signos ideológicos. De onde se conclui que a palavra é o modo mais puro e sensível de relação social e instrumento de consciência. Daí a proximidade da filosofia Bakhtiniana à proposta da Justiça restaurativa.

O Círculo, portanto, olha para o diálogo face a face do mesmo modo que olha para uma obra literária, um trato filosófico, um texto religioso, isto é, como eventos da grande interação sociocultural de qualquer grupo humano... (FARACO, 2009, p. 62).

A teoria de Bakhtin sobre o dialogismo influenciou significativamente o estudo da linguagem e várias disciplinas. Para esse autor, dialogismo é a ideia de cultura, de existência mesma do ser humano, como 
ser de linguagem. A linguagem envolve os sujeitos, daí a ideia de que a linguagem consiste de muitas vozes, muitas conotações e distintos contextos sociais. O falar e o ouvir são os sentidos que levam os sujeitos a se entregarem de coração, ligando-os a si mesmos e a outros de maneira tal que permitem que a compaixão natural floresça.

Assim, neste limiar de discussão, cabe relembrar o objetivo e o conceito da Comunicação-Não-Violenta de Rosenberg (2003): os seres humanos deveriam relacionar-se uns com os outros e viver de modo que se possa reformular a maneira pela qual as pessoas se expressam e ouvem os demais. Aqui surge a narrativa: ela não é só um gênero literário, ela é parte do modo humano de ser e de estar no mundo. As narrativas que começaram em volta do fogo, nos primórdios da humanidade, são usadas até hoje como método de união, como conceito de comunidade.

Rosenberg (2003) enfatiza que as palavras, ao invés de serem reações repetitivas e automáticas, devem ser respostas conscientes, firmemente ancoradas na consciência do que estamos percebendo, sentindo e desejando, levando-nos a expressarmos com honestidade e clareza, ao mesmo tempo em que damos aos outros uma atenção respeitosa e empática. Assim também se entende que as narrativas devem ser.

\section{CírCUlos de CONSTRUÇÃo de PAZ: DIREITOS FUNDAMENTAIS}

Balim et al. (2014) explicitam que foi a Resolução n. 12/2002, da Organização das Nações Unidas, que institucionalizou os princípios básicos dos programas de justiça restaurativa, que apontavam que os Estados deveriam implantar projetos restaurativos a fim de evitarem as violações a direitos e garantias individuais. Os mesmos autores também relatam que no Brasil essa iniciativa emergiu, em 2005, na Carta de Araçatuba, ratificada posteriormente na Conferência Internacional: Acesso à Justiça por Meios Alternativos de Resolução de Conflitos e que ficou, por sua vez, conhecida como Carta de Brasília.

A justiça restaurativa surgiu recentemente, utilizando a prática dos círculos dialógicos. Ela tem sido vista como uma prática social potencialmente transformadora que pode ver o fim para a necessidade de du- 
ras punições penais e encarceramento para diferentes fenômenos. Nesse sentido, ela seria, então, um salto quântico, transcendendo as ideologias repressiva e sociológica, onde o caráter punitivo e retributivo imperam, não dando margem à recuperação e à reparação efetiva tanto da vítima, como da sociedade e do ofensor. Isso reforça os procedimentos da Justiça Restaurativa, com os "Processos Circulares", círculos que oferecem um processo ordenado e reflexivo que reforça valores positivos (AMSTUTZ e MULLET, 2012).

O processo circular está enraizado em tradições antigas e tem o aporte de conhecimentos contemporâneos sobre a vida em sociedades multiculturais que mudam com rapidez. As comunidades antigas usavam processos similares aos Círculos para tratar do trabalho da comunidade - como é costume em muitas comunidades indígenas em todo o mundo. Acredita-se que sejam uma forma comum de engajamento coletivo em torno de questões de interesse da comunidade em todos os tempos e lugares. Os processos circulares descritos aqui descendem mais diretamente das tradições de vários povos das Primeiras Nações, pessoas que ainda usam os Círculos e encarnam ensinamentos centrais relacionados aos Círculos em seu modo de vida. O processo circular também é formado por experiências modernas de diálogo, criação de consenso, comunicação intercultural, reconhecimento de interesses individuais, teoria das mudanças e transformação pessoal. O processo é um equilíbrio entre o antigo e o contemporâneo, o indivíduo e o grupo, o ser interno e o externo.

O círculo é uma técnica para organizar de modo eficiente a comunicação grupal, para construir relacionamentos, tomar decisões e resolver conflitos. Ainda mais importante, o círculo encarna e nutre uma filosofia de relacionamento e interconexão, que pode nos guiar em todas as circunstâncias - dentro e fora do círculo. O Círculo cria um espaço protegido, é a figura que não tem hierarquia nem começo nem fim. É o que permite praticar o comportamento ancorado em valores daquele "melhor de si" naquelas ocasiões em que pareceria arriscado fazê-lo. Quanto mais as pessoas praticam esse comportamento no Círculo, tanto mais esses hábitos são reforçados e levados para outras regiões de suas vidas. 
Nas suas mais variadas formas e objetivos, os processos circulares têm na palavra sua fonte de integração entre os envolvidos em litígios e conflitos. Como a Justiça restaurativa também pode ser explicada como uma abordagem da justiça que visa satisfazer as necessidades das vítimas e dos infratores, bem como, a toda a comunidade, pode-se afirmar que ela é um processo pelo qual todas as partes que têm uma participação no delito específico resolvem coletivamente sobre como lidar com as consequências.

Os principais elementos desses processos são:

- Reunião: as partes muitas vezes se encontram pessoalmente, embora em algumas circunstâncias seja realizado com a participação de um terceiro, um substituto.

- Narrativa: as pessoas que vêm falar sobre o que aconteceu, como foram afetadas, e como lidar com o malfeito.

- Emoção: considera como um elemento facilitador para a compreensão, modificando a ênfase na racionalidade existente nos tribunais.

- Compreensão: as partes chegam a compreender melhor uma à outra, o ato lesivo, o dano causado pelo ato lesivo, e como corrigir a situação.

- Acordo: quando as partes são capazes de explorar as repercussões pessoais, materiais, morais e espirituais do ato lesivo, eles, então, planejam um acordo específico para a situação.

Para Bakhtin, a palavra é a expressão máxima da ação responsável, ainda que não dita:

O "não álibi do ser" coloca o eu em relação com o outro, não segundo uma relação indiferente com o outro genérico e enquanto ambos exemplares do homem em geral, mas enquanto coenvolvimento, relação não indiferente com a vida do próprio vizinho, do próprio contemporâneo com o passado e o futuro de pessoas reais (MIOTELO e FARACO, 2010, p. 27). 
Para os defensores da justiça restaurativa, o crime é percebido como uma violação de pessoas e relações, e o seu objetivo é reparar todos os danos sofridos por vítimas, infratores e comunidades, adaptando-se às peculiaridades locais, conforme explicitam Balim et al. (2014), das quais decorrem valores e princípios essenciais para a efetivação dos direitos e garantias individuais. Assim, o autor do delito impõe ao outro que ele ofendeu a sua "carga" de responsabilidade social, mostrando que, embora seja o homem fruto de seu meio, este fato, por si só, lhe impõe o encargo de atuar na construção da sociedade a que pertence.

\begin{abstract}
A filosofia moral, que Bakhtin qualifica como "filosofia primeira", deve descrever "a arquitetônica concreta" em que a indiferença do indivíduo abstrato, genérico, intercambiável, substituível na sua responsabilidade estabelecida e circunscrita à sua presença a um todo, a um gênero, à sua adjudicação a uma determinada tipologia substitui a não indiferença do indivíduo tornando-o único apenas por ser insubstituível na sua responsabilidade diante da qual o acontecimento de sua existência, sem álibi, o põe (MIOTELO e FARACO, 2010, p. 28). ${ }^{1}$
\end{abstract}

É exatamente dessa forma que os círculos de construção de paz atuam nos Círculos Restaurativos, pois a fala é muito considerada. É o momento em que as partes em conflito podem exprimir os seus sentimentos, indignações e desejos: a responsabilidade da existência de cada um e de sua relação com o outro.

O outro, seja ele vítima ou ofensor, tem voz e ela é ouvida e sentida. Assim, como no Círculo de Bakhtin, o outro se torna tão central no pensamento, porque o(s) interlocutor(es) real(is) ou presumido(s) não é(são) passivo(s). Ao perceber e compreender o significado (linguístico) do discurso, o interlocutor ocupa simultaneamente em relação ao locutor uma ativa posição responsiva:

1 Prefácio ao livro Por uma Filosofia do Ato Responsável, de Mikhail Bakhtin, Pedro e João Editores. Campinas: 2010. 
Toda compreensão da fala viva, do enunciado vivo é de natureza ativamente responsiva (embora o grau desse ativismo seja bastante diverso); toda compreensão é prenhe de resposta, e nessa ou naquela forma a gera obrigatoriamente: o ouvinte se torna falante (BAKHTIN, 2006, p. 271).

Tendo por premissas que todos querem estar ligados aos outros de modo positivo; que todos são membros valiosos da comunidade e têm direitos às suas crenças e, que todos têm valores centrais que indicam o que significa estar ligado ao outro de modo positivo (muito embora nem sempre seja fácil agir segundo esses valores, principalmente em tempos de conversas difíceis ou conflitos), os processos circulares trazem aos participantes a responsabilidade individual.

Rosenberg leciona que:

...quando nos entregamos de coração, nossos atos brotam de alegria que surge e resplandece sempre que enriquecemos de boa vontade a vida de outra pessoa. Isso beneficia tanto quem doa quanto quem recebe. Este último aprecia o presente sem se preocupar com as consequências que acompanham o que foi dado por medo, culpa, vergonha ou desejo de lucrar alguma coisa. Quem doa se beneficia daquele reforço de autoestima que se produz sempre que vemos nossos esforços contribuírem para o bem-estar de alguém (ROSENBERG, 2006, p. 24).

Vários tipos de círculos de construção de paz são propostos por Kay Pranis (2011, p. 28):

Círculo de Diálogo - Num círculo ou roda de diálogo os participantes exploram determinada questão ou assunto a partir de vários pontos de vista. Não procuram consenso sobre o assunto. Ao contrário, permitem que todas as vozes sejam ouvidas respeitosamente e oferecem aos participantes perspectivas diferentes que estimulam suas reflexões. 
- Círculo de Compreensão - Esta é uma roda de diálogo que se empenha em compreender algum aspecto de um conflito ou situação difícil. Em geral ele não é um Círculo de tomada de decisão e, portanto, não precisa buscar um consenso. Seu propósito é desenvolver um quadro mais completo do contexto ou das causas de um determinado acontecimento ou comportamento.

- Círculo de Restabelecimento - O objetivo deste círculo é partilhar a dor de uma pessoa ou grupo de pessoas que vivenciaram um trauma ou uma perda. Poderá surgir um plano de ajuda, mas este não é um requisito necessário.

- Círculo de Sentenciamento - Este é um processo dirigido à comunidade, em parceria com o sistema de justiça criminal. Oferece aos que foram afetados por um crime ou ofensa a oportunidade de elaborar um plano de sentenciamento adequado, que contemple as preocupações e necessidades de todos os envolvidos.

Todos eles têm em comum a fala dos participantes expondo os seus pontos de vista, anseios, perspectivas e uma forma comunitária de solução de conflitos. Contudo, a realização de um círculo de construção de paz necessita de elementos estruturais para criar um espaço seguro, onde as pessoas se liguem umas às outras de modo positivo, mesmo em circunstâncias de conflito, dano ou dificuldades.

Esses elementos são: i) as cerimônias: que podem ser de abertura ou encerramento - marcam o tempo e o espaço do círculo como um lugar a parte; ii) as orientações: são compromissos ou promessas que os participantes fazem uns aos outros quanto ao modo como se comportarão no círculo; iii) o bastão da fala: processo decisório consensual, pois entendo que são nesses dois elementos que a filosofia bakhiniana mais se aproxima e iv) a facilitação/guarda: exercida por uma pessoa que tem como função envolver os participantes na partilha da responsabilidade pelo espaço e pelo trabalho comum. 


\section{- a narratividade e a voz das vítimas: o bastão da fala}

$\mathrm{O}$ bastão é um símbolo fálico por excelência. É o cajado dos peregrinos, o cetro dos reis, a vara mágica e o instrumento de cura do xamã.

Pranis (2010) explica que o bastão da fala é um objeto que passa de pessoa para pessoa, dando a volta no círculo, dando a oportunidade ao seu detentor de falar, enquanto os outros participantes têm a oportunidade de escutarem sem pensar em uma resposta.

O bastão da fala tem sido usado há séculos por povos indígenas americanos, como um meio de fala e escuta justa e imparcial. Era utilizado comumente em reuniões de conselho circulares para designar quem tinha o direito de falar. Quando assuntos de grande importância vinham à frente do conselho, o chefe da tribo pegava o bastão e iniciava a discussão. Ao término de sua fala, ele passava o bastão para alguém que desejasse falar, assim o bastão passava de um indivíduo para outro, até que o bastão voltasse novamente ao chefe da tribo, para que ele pudesse guardá-lo em lugar seguro (LOCUST, 2009). O bastão é a garantia de ser ouvido, da liberdade de expressão e da segurança pessoal.

Dignan (2011) descreve cinco pontos distintos que beneficiam vítimas na justiça restaurativa: as vítimas tornam-se envolvidas no processo, isso lhes dá uma sensação de satisfação e crença no sistema, em oposição ao sistema de Justiça convencional que os remove completamente do processo; outra coisa é que se o infrator oferece suas sinceras desculpas, e se é aceito pela vítima, isso pode até conduzir ao perdão e ter um efeito de cura, que, por sua vez, pode conduzir à reconciliação total. Esse diálogo frente a frente é uma construção da linguagem de cada um.

Bakhtin entende que cada um dos pensamentos do sujeito é um ato singular e responsável, considerando que a vida em sua totalidade é uma espécie de ato complexo, e cada ato singular e cada experiência de vida é um momento do viver-agir, formando um todo integral:

Tal pensamento, enquanto ato forma de um todo integral: tanto o seu conteúdo-sentido quanto o fato de sua presença em minha consciência real de um ser humano singular, precisamente determinado e em condições 
especiais, ou seja, toda a historicidade concreta de sua realização, estes dois momentos, portanto, seja o do sentido, seja o histórico-individual (factual), são dois momentos unitários inseparáveis na valoração deste pensamento como meu ato responsável (BAKHTIN, 2012, p. 44).

Assim, o bastão da fala, por desacelerar o ritmo da conversa e estimular a interação, proporcionando a reflexão, cuidado e emoções entre os participantes, vai ao encontro do pensamento de Bakhtin:

Eu, que realmente penso e sou responsável pelo ato do meu pensar não tem lugar no juízo teoricamente válido. O juízo teoricamente valido é, em todos os seus momentos, impenetrável para a minha atividade individualmente responsável (BAKHTIN, 2012, p. 45).

Estar de posse do bastão da fala deve ser uma experiência segura para que o detenha, possibilitando expor pensamentos e sentimentos de sua experiência de vida, associando-os ao contexto proposto pelo círculo.

Portanto, é nesse momento que o possuidor do bastão irá narrar o experimento vivido, seus motivos e consequências, fazendo-se ouvir, sem interferências, mas interagindo com os demais integrantes do círculo.

\section{- diálogo e sentido: reconstrução de vidas}

Como já mencionamos, toda existência humana é uma vida em busca de uma narrativa e a partilha de histórias pessoais é a fonte essencial do poder dos círculos. Esses constroem relacionamentos, exploram problemas e partilham sabedoria e experiências de vida dos participantes.

Vítimas inseridas nos círculos de restauração podem querer recuperar um senso de empoderamento, ou ainda confrontar o agressor e explicar o impacto do crime. As vítimas ainda podem expor as suas emoções extremas ou fazer perguntas básicas ao ofensor (por que eu?), ou ajudar o ofensor a compreender a extensão do mal que causou, ou simplesmente para satisfazer sua curiosidade. 
Vários tipos de narrativas emergem dos participantes dos círculos e a-contação de histórias pode ser uma ferramenta poderosa para transformar relacionamentos. Ela permite que os participantes vejam uns aos outros sob um prisma multidimensional, que em geral derruba preconceitos ou pressupostos que impedem a boa comunicação. A contação de histórias envolve o coração e o espírito mais do que o fariam dados e informações.

Bakhtin compreende na comunicação que o tom da voz e uma série de códigos implícitos que são percebidos pelos interlocutores fazem diferentes efeitos e sentidos. Pois, em um diálogo não há passividade nem no sujeito do discurso, tampouco no ouvinte, visto que:

(...) toda compreensão plena e real é responsiva e não é senão uma fase inicial preparatória da resposta (seja qual for a forma que ela se dê). O próprio falante está determinando precisamente a essa compreensão ativamente responsiva: ele não espera uma compreensão passiva, por assim dizer, que apenas duble o seu pensamento em voz alheia, mas uma resposta, uma concordância, uma participação, uma objeção, uma execução, etc. (os diferentes gêneros do discurso pressupõem diferentes diretrizes de objetivos, projetos de discurso dos falantes ou escreventes)" (BAKHTIN, 2010, p. 272).

Agora, no que diz respeito ao processo decisório consensual, na teoria bakhtiniana, a noção de atividade (humana) está circunscrita, entre outras, na noção de ato ético e responsável em cujo centro axiológico há um movimento permanente de valores.

O sujeito é um centro de valor em relação: eu-para-mim, outro-para-mim, eu-para-outro, que, ocupando um lugar único (espacial e temporal) na tessitura valorativa concreta, assim, um processo com outros membros reais, "interconectados por relações-eventos no evento único do Ser” (FANTI, 2012, p. 315).

Nesse passo, temos que nos Círculos Restaurativos todos os envolvidos buscam tratar o ato lesivo e as suas causas, buscando reparar 
os danos causados, através do reconhecimento de suas dores pessoais e da responsabilização, não só do agente, mas de todos os envolvidos, pois a ideia é de uma interação social e responsável. Todos cuidam dos danos sofridos pela vítima, pois assim o ofensor pode corrigir, responsavelmente, seu ato delituoso (ZEHR, 2012).

Um Círculo Restaurativo de tomada de decisão em grupo concentra-se em chegar a uma decisão consensual. Nesse caso, a preparação é parte importante do processo, e poderá exigir a realização de Círculos de Compreensão e Círculos de Formação de Espírito Comunitário antes que se reúna o grupo para a tomada de decisão. Grupos de trabalho, conselhos diretores, conselhos consultivos e famílias vêm usando esses Círculos de Tomada de Decisão para tomar decisões importantes no escopo de suas comunidades. As decisões tomadas nos Círculos Restaurativos podem servir de embasamento para decisões judiciais, dependendo da gravidade do ato lesivo, sendo que, em alguns casos, até ser substituídas, pois a consciência do ofensor, aliada à forma de reparação do dano, podem traduzir o sentenciamento que determina a própria lei.

Afinal, a ideia primeira da Justiça Restaurativa é, por meio do diálogo, buscar corrigir falhas no sistema tradicional da concepção de justiça retributiva, que não cuida da vítima, não cuida do ofensor e tem uma concepção linear do conflito. Na linha da garantia dos direitos humanos, a prática restaurativa busca um olhar mais humano sobre aquele que praticou o ato ilícito, sobre a vítima e as demais relações humanas que nele se entrelaçam.

Quando é preciso tomar uma decisão num círculo, essa decisão deve ser consensual. Num círculo, o consenso significa que todos podem viver com aquela decisão e apoiá-la. Talvez aquela decisão não seja o ideal para todos, mas ela precisa ser aceitável para todos. A eficácia do processo consensual depende de uma sólida visão partilhada, equidade de vozes e relacionamentos de confiança entre os participantes.

Pelo fato de os círculos serem fundados sobre valores partilhados, oferecerem voz igual para todos por meio do bastão de fala, e construírem relacionamentos ao longo de todo o processo, chegar a um consenso no círculo não é tão difícil como a maioria das pessoas imagina. As decisões 
consensuais têm uma vantagem significativa sobre as decisões impostas por voto da maioria. Elas são muito mais fáceis de implementar porque todos estão empenhados e unidos na intenção de fazê-la funcionar.

\section{Considerações Finais}

Ao fim deste texto, conclui-se que um círculo restaurativo ou de construção de paz é fundado no diálogo, dentro dos princípios apresentados das teorias linguísticas dos Círculos bakhtinianos. Viu-se que o diálogo nos círculos de construção de paz promovem a liberdade de expressão, o direito à presunção de inocência e à defesa, a restauração da dignidade da pessoa humana, seja vítima ou o ofensor, ou ainda a comunidade.

Os círculos partilham dificuldades e constroem valores, identidade e alteridades, pois sua finalidade é congregar as pessoas, estabelecer vínculos para resolver problemas e chegar a entendimentos, e, até mesmo, fortalecer relacionamentos.

Muitos esforços têm sido feitos para dar às vítimas um papel mais central no sistema de justiça criminal, e inseri-las num diálogo frente a frente com o ofensor e os círculos podem ser uma alternativa exitosa, principalmente porque aí se dá a linguagem, a interação entre o ofensor e a vítima. As vítimas deixam o seu papel de testemunhas vulneráveis e adquirem a voz como participante do processo de sua restauração como sujeito de uma sociedade mais legítima, inserindo-se na sua narratividade de ofendido.

As narrativas são seres de linguagem, são práticas sociais que têm na língua a sua realidade material, são entendidas como um processo de evolução ininterrupto, constituído pelo fenômeno social da interação verbal, realizada através da enunciação, que é a sua verdadeira substância.

A justiça restaurativa leva abordagens pessoais, palavras e narrativas carregadas emocionalmente, muitas vezes ausentes nas cortes, estimula sentimentos de responsabilidade por parte do autor da infração.

O Grupo de estudos de Bakhtin existiu com ele a vida toda. Foi por meio dessa metodologia que se desenvolveram pesquisas e discussões filosóficas, sempre com caráter científico. Era no diálogo de ideias 
que se produzia ciência. Algumas vítimas vulneráveis têm dificuldades de se comunicar (falta de discurso ou discurso limitado), dificuldade com tarefas básicas (ler, escrever ou contar o tempo), dificuldade com a memória, ou emoções extremas, por isso o bastão da fala pode proporcionar um momento de participar de um programa de restauração. $\mathrm{O}$ círculo é um espaço de poder compartilhado, onde as pessoas chegam de livre e espontânea vontade; em que ninguém é culpabilizado, e onde os participantes assumem responsabilidade pelo acontecido e chegam a um acordo que restaure a relação rompida.

Todos estão profundamente interligados e adotar essa visão de mundo significa uma mudança enorme de perspectiva e que não há saída fácil evitando-se o conflito ou ignorando os problemas. Mas essa visão pode também representar uma disposição extremamente positiva, pode significar que jamais estamos sozinhos. Sempre pertencemos não importa o que aconteça.

Nos círculos, a narrativa impera com o intuito de unir as pessoas, solucionar problemas, e desenvolver o ser humano. Dessa forma, não podemos desconsiderar que a busca, incessante, do ser humano em firmar suas relações passa, necessariamente, pela narrativa.

A narrativa quer sendo ciência (no Círculo Bakhtiniano), ou como forma de solução de conflito (Círculo Restaurativo), é que faz os participantes se envolverem entre si, compartilhando experiências, propondo resultados, descobrindo novos aspectos introspectivos do ser humano. Falar, expressar-se, é ainda a forma mais eficaz de edificar as relações humanas.

\section{REFERÊNCIAS}

AMSTUTZ, Lorraine Stutzaman e MULLET, Judy H. Disciplina restaurativa para escolas. Tradução Tônia Van Acker. São Paulo: Palas Athena, 2012.

BAKHTIN, Mikhail Mikhailovch. Para uma Filosofia do Ato Responsável, 2. ed. Tradução de Valdemir Miotello \& Carlos Alberto Faraco. São Paulo: 
Pedro \& João Editores, 2012.

. Marxismo e filosofia da linguagem, 13. ed. Tradução de Michel Lahud e Yara Frateschi Vieira. São Paulo: Ed. Hucitec, 2009.

BALIM, Ana Paula C., MENDES, Cláudia M. R., MOTA, Luiza R. Justiça Restaurativa: uma medida alternativa para o modelo tradicional de justiça penal. In: XI Seminário Internacional de Demandas Sociais e Políticas Públicas na Sociedade contemporânea e VII Mostra de Trabalhos Jurídicos Científicos. Universidade Santa Cruz do Sul, 2014. Disponível em: https://online.unisc.br/acadnet/anais/index.php/sidspp/article/view/11817/1654. Acessado em 5.12.2017.

DI FANTI, Maria da Glória Corrêa. Linguagem e trabalho: diálogo entre a translinguística e a ergologia. Revista do Programa de Pós-Graduação em Letras da Universidade de Passo Fundo, v. 8, n. 1, p. 309-329, jan./jun. 2012. Disponível em: http://seer.upf.br/index.php/rd/article/viewFile/2651/1813. Acessado em: 23.07.2017.

DIGNAN, J. The victim in restorative justice. In: Sandra Walklate (Org.). Handbook of Victims and Victimology (chapter 12, p. 309-331). Cullompton: Routledge, 2011.

FARACO, Carlos Alberto. Linguagem \& Diálogo: As ideias do Círculo de Bakhtin. São Paulo: Parábola editorial, 2009.

. Um posfácio meio impertinente. In: BAKHTIN, M. Para uma filosofia do ato responsável (1920-1924). Tradução Valdemir Miotello e Carlos Alberto Faraco. São Carlos: Pedro \& João Editores, 2010.

KEARNEY, Richard. Narrativa. In: Educ. Real, Porto Alegre, v. 37, p. 409/439, mai./ago. 2012. Disponível em: http://www.ufrgs.br/edu_realidade. Acessado em: 23.07.2017.

LOCUST, Carol. O Bastão da Fala - utilizado nas reuniões dos grupos de apoio da AADA. Disponível em: http://www.aada.org.br/page_saibamais. php?tipo=artigo\&id=4. Acessado em: 22.07.2017.

MOLON, Newton D. e VIANNA, Rodolfo. O Círculo de Bakhtin e a Linguística Aplicada. Disponível em: http://revistas.pucsp.br/index.php/bakhtiniana/article/view/9890. Acesso em 23.07.2017. 
PEÑA, H. Mediación narrativa: técnicas y método para resolver conflictos en las organizaciones. DIXI 17 (22), 1-22, 2015.

PRANIS Kay. Processos Circulares. São Paulo: Ed. Palas Athena, 2010a.

ROSENBERG, Marshall B. Comunicação não violenta. São Paulo: Ed. Ágora, 2006.

ZEHR Haward. Justiça Restaurativa. São Paulo: Ed. Palas Athenas, 2012.

\section{SOBRE OS AUTORES}

\section{Valéria Bressan Candido}

Doutoranda em Educação pela Universidade Metodista de São Paulo, Mestre em Políticas Públicas pela Universidade de Mogi das Cruzes, Especialista em Direito Público, Docente no Programa de Pós-Graduação em Gestão de Políticas Públicas da Faculdade Inovare de Poá, Assistente Jurídico no Tribunal de Justiça do Estado de São Paulo.

CV: http://lattes.cnpq.br/7610253415034768

E-mail: valbressan@uol.com.br

\section{Luci Mendes de Melo Bonini}

Doutora em Comunicação e Semiótica pela PUC-SP, docente nos programas de Mestrado em Políticas Públicas da Universidade de Mogi das Cruzes e do Mestrado em Habitação: Planejamento e Tecnologia do Instituto de Pesquisas Tecnológicas de São Paulo - IPT-SP.

CV: http://lattes.cnpq.br/1281239421952609

E-mail: lucibonini@gmail.com.

Submetido em:23-7-2017

Aceito em: 22-2-2018 